\title{
Local fuel concentration measurement through spark-induced breakdown spectroscopy in a direct-injection hydrogen spark-ignition engine
}

\author{
Kazi Mostafijur Rahman*, Nobuyuki Kawahara, Daichi Matsunaga, Eiji Tomita \\ Heat Power Engineering Laboratory, Okayama University, Tsushima Campus, Okayama 700-8530, \\ Japan \\ Yasuo Takagi, Yuji Mihara \\ Research Centre for High Efficiency Hydrogen Engine \& Engine Tribology, Tokyo City University, \\ 1-28-1 Tamazutsumi, Setagaya-ku, Tokyo 158-8557, Japan
}

\begin{abstract}
Quantitative measurements of local fuel concentrations were conducted in a directinjection hydrogen spark-ignition research engine using the spark-induced breakdown spectroscopy (SIBS) technique. For SIBS measurements, a new sensor was developed from a commercially available M12-type spark plug with no major modifications to the electrodes. The new plug sensor showed better durability and required less maintenance when used in a hydrogen research engine. Emission spectra from the plasma generated by the spark plug were collected through an optical fibre housed in the centre electrode of the plug and resolved spectrally for atomic emissions of $\mathrm{H}_{\alpha}, \mathrm{O}(\mathrm{I})$, and $\mathrm{N}(\mathrm{I})$. The main focus of the present work was to characterise the effects of ambient pressure at ignition timing on spectral line emissions and to improve the accuracy of SIBS measurements by taking into account the pressure dependency of atomic emissions. A significant effect of the corresponding pressure at ignition timing was observed on spark-induced breakdown spectroscopic measurements and emission line characteristics. Retarded spark timing (i.e. higher ambient pressure at the ignition site) resulted in lower spectral line intensities as well as weaker background emissions. It is well established that with relatively higher pressure and density of atoms or molecules, the cooling of expanding plasma accelerates, and the collision probability increases, leading to both a weaker broadband
\end{abstract}

(C) 2016. This manuscript version is made available under the Elsevier user license 
continuum and atomic emissions. A "calibration MAP" representing the correlation of air excess

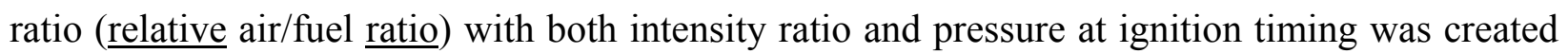
and subsequently used for quantitative measurements of local fuel concentrations for both port injection and direct injection strategies to demonstrate and explore the effects of pressure dependency of atomic emission on the accuracy of the SIBS measurements. Local stratification of the fuel mixture in the vicinity of the spark gap location associated with direct injection strategies was confirmed; the coefficient of variation of the local air excess ratio was relatively small for measurements made using the calibration map. This demonstrated that the measurement accuracy of local fuel concentrations through a spark plug sensor can be improved significantly when the pressure dependency of atomic emissions is taken into account.

Key words: Atomic emission; hydrogen direct injection; local fuel concentration; spark-induced breakdown spectroscopy; spark plasma

\section{Introduction}

Hydrogen has long been considered as one of the most promising energy carriers and investigated as a fuel for internal combustion engines (ICEs) due to its potential for high engine efficiency and greenhouse gas reduction [1-5]. There are some initiatives in Japan to move towards the "dream of a hydrogen-based society" and to accelerate the installation of hydrogen stations for fuel-cell vehicles that run on electricity, generated by burning hydrogen. Today, various governments, especially in Europe, the United States, Canada, and Japan, are taking leading roles in establishing and promoting low carbon electricity generation through cogeneration systems. Until now, hydrogen-fuelled cogeneration has been dominated by fuel cell applications, and the high cost of these systems has been a limiting factor for hydrogen's 
viability as a fuel for stationary power applications [6-9]. However, reciprocating hydrogenfuelled engines that can offer an economic proposition comparable to natural gas and diesel could establish hydrogen-fuelled cogeneration system as a viable alternative. Obara et al. investigated a hybrid cogeneration system (HCGS) by combining a solid polymer membranetype fuel cell (PEM-FC) and a hydrogen mixture gas engine (NEG) [10]. They reported improvement in power generation efficiency and reduction in carbon dioxide emission.

Much research has focused on hydrogen direct-injection spark-ignition (DISI) engines due to their high volumetric efficiency and potential to avoid knock, preignition, and backfiring, which have detrimental effects on engine performance and emissions [11-14]. Optimisation of spark timing, injection timing, and injection pressure, are important aspects of the development of hydrogen DISI engines [15] and can suppress backfiring and knocking, especially at higher engine loads. Oikawa et al. reported a "plume ignition combustion concept" (PCC) for hydrogen DISI engines, denoting the ignition of a rich mixture plume during or right after an injection event [16]. In their study, the injector was mounted close to the spark plug to achieve jet-guided combustion with the jet being directed towards the spark plug using high injection pressures (200 bar). This PCC combustion with late injection strategy was shown to substantially reduce $\mathrm{NO}_{\mathrm{x}}$ emissions at high speed and under high load conditions while maintaining high thermal efficiency and power. A major challenge in the use of $\mathrm{H}_{2}$-DI is in-cylinder hydrogen-air mixing. The local equivalence ratio near the spark plug at the time of the spark discharge is particularly important for successful ignition, because the jet-guided system generates a stratified fuel concentration near the spark plug in a DISI engine. In addition, the mixture distribution around the spark plug, together with fluid motion, strongly influences the combustion initiation, which subsequently affects the engine performance, efficiency, and emissions. Thus, a fundamental 
understanding of mixture formation processes is necessary to optimise DI- $\mathrm{H}_{2}$ ICE operation. To better understand how to both achieve an optimal local mixture and control the large-scale stratification, a diagnostic tool for providing information on the mixture distribution in practical engines should be developed. Instantaneous fuel concentration measurements in production engines will greatly aid in engine design and optimisation.

There are several approaches to studying fuel concentrations in an SI engine, including infrared (IR) absorption, planar laser induced fluorescence (PLIF), Raman scattering, laser-induced breakdown spectroscopy (LIBS) and spark-induced breakdown spectroscopy (SIBS) or spark emission spectroscopy. A 3.392- $\mu \mathrm{m}$ He-Ne laser was used to obtain fuel concentrations for combustion diagnostics [17-26]. One of the members of our group was the first to investigate the possibility of measuring fuel concentration near the spark plug in a test engine [21]. Subsequently, Tomita et al. used an optical sensor with a pair of sapphire rods to pass laser light through the combustion chamber of a practical engine; they also discussed several of the factors that affected measurement accuracy [22,23]. Their sensor has also been applied to practical SI engines and direct-injection gasoline engines [24]. We developed an optical spark-plug sensor with a double-pass measurement length using an infrared absorption technique for measuring hydrocarbon fuel concentrations [25,27]. LIF measurements have been used widely because the LIF signal is relatively strong and provides two-dimensional fuel concentration information at a specified time [28-30]. Tomita et al. [28] applied the PLIF method to study the fuel concentration distribution in a transient hydrogen jet. Results showed that each transient hydrogen jet had different configurations and concentration distributions. Kaiser and White [30] performed an optical study of mixture preparation in a hydrogen-fuelled engine using a PLIF technique; their report favoured increased injection pressure and careful nozzle design. Ferioli et 
al. [31] used LIBS on engine exhaust gas to illustrate the ability of this technique to measure the equivalence ratio of SI engines, using the ratios of $\mathrm{C} / \mathrm{O}$ and $\mathrm{C} / \mathrm{N}$ atomic peaks derived from the measured spectra. Phuoc [32] used a laser-induced spark to measure the ignition and fuel-to-air ratio of $\mathrm{CH}_{4}$-air and $\mathrm{H}_{2}$-air combustible mixtures simultaneously using the measured spectral peak ratio $\mathrm{H}_{\alpha}(656 \mathrm{~nm}) / \mathrm{O}(777 \mathrm{~nm})$. Shudo and Oba [33] measured the mixture formation characteristic with a hydrogen jet in a nitrogen-filled constant-volume chamber using LIBS techniques. We have also tried to measure the equivalence ratio using LIBS and discussed the accuracy of spatially, temporally, and spectrally resolved measurements [34,35]. However, IR absorption is not suitable for measuring the hydrogen/air ratio due to the lack of absorption bands at visible and infrared wavelengths. PLIF and LIBS require major engine modifications including optical access, which limit their application to production engines. Quantitative measurements of the cycle-to cycle variations in the mixture strength at or near the ignition site are comparatively rare for practical hydrogen SI engines.

With SIBS, the signal detection and spectroscopy is similar to LIBS; however, spark generation occurs between two electrodes, in which the spark itself is used as the light source to estimate the equivalence ratio in the spark plug. SIBS can therefore be used in a combustion chamber with no engine modifications, because the plasma excitation can be implemented using a conventional spark plug. Spark-emission spectroscopy has been applied to measure the equivalence ratio in a $\underline{\text { DISI engine [36-38]. Ando and Kuwahara [37] and Fansler et al. [38] reported individual }}$ measurements of the equivalence ratio at the spark gap using the ratio of $\mathrm{CN}$ (388 nm) emission intensity and $\mathrm{OH}(306 \mathrm{~nm})$ radical intensity from the spark that initiates combustion. They determined the cycle-resolved local fuel-air ratio in the spark gap, controlled the large-scale $\underline{\text { stratification, and evaluated the utility of SIBS as an engine diagnostic tool. However, it is }}$ 
difficult to detect the equivalence ratio under lean mixture conditions due to lack of the linearity of $\mathrm{CN} / \mathrm{OH}$ emission intensity ratio. All of these studies require engine modification for optical access to the combustion chamber from outside. Kawahara et al. [39] used the SIBS technique to measure the local equivalence ratio in a laminar premixed flame of a $\mathrm{CH}_{4} /$ air mixture. Spectrally resolved emission spectra of plasma generated by a spark plug were investigated for their potential to measure local fuel concentrations in a premixed mixture. The spectrum was measured through an optical fibre housed in the centre electrode of the spark plug, which makes this technique suitable for measuring the equivalence ratio in the spark gap at ignition timing, in production engines without engine modification. Roy et al. [40] further improved the spark-plug sensor to measure the local fuel-air concentration in the spark gap at the time of ignition in a fired, jet-guided hydrogen SI-engine operated under stratified-charge conditions using SIBS. Tasyrif et al. [41] investigated the mixing process of a hydrogen jet in a constant-volume vessel and characterised the spatial distribution of the equivalence ratio across the jet and along its axis. Later, they reported the effects of the ambient pressure on fuel concentration measurements of an injected jet of hydrogen into a nitrogen environment with different ambient pressures; also, local concentrations were measured at various spark locations in a constant-volume vessel [42].

In this study, SIBS measurements were conducted in a direct-injection hydrogen spark-ignition research engine for the first time. The 'plume ignition combustion concept' was used to achieve high thermal efficiency along with a substantial reduction in $\mathrm{NO}_{\mathrm{x}}$ emissions under high load conditions. A new spark plug sensor was developed from a commercially available M12-type spark plug with no modification to the ground electrode, whereas in the previous spark plug sensor, the ground electrode was made separable from the thread reach, leading to unstable spark formation outside of the measurement area, especially at high ambient pressures. In the present 
work, we sought to characterise the effects of ambient pressure at ignition timing on spectral line emissions and to improve the accuracy of SIBS measurements by taking into account the pressure dependency of atomic emissions. Spectrally resolved emission spectra of plasma generated by a spark plug were measured through an optical fibre housed in the centre electrode of the spark plug. First, the correlation between the air excess ratio (or the relative air/fuel ratio) and atomic emission intensity ratio (also known as a calibration curve or calibration line) was examined for different pressures during ignition under port injection conditions. A calibration map representing the correlation of air excess ratio (air/fuel) with both intensity ratio and pressure at ignition timing was created by taking into account the effect of the corresponding pressure at ignition on spectral line intensity. The calibration line and calibration map were subsequently used for quantitative measurements of the local air excess ratio for both port injection and direct injection strategies to investigate the effects of the corresponding pressure at ignition timing on the accuracy of SIBS measurements.

\section{Experimental set-up}

\subsection{Research engine}

The engine experiments were conducted using a single cylinder research engine, designed and built at Tokyo City University (TCU) [16]. The major specifications of the engine are described in Table 1. The combustion chamber geometry, orientation of the injector, and the spark plug are shown in Fig. 1. A bowl-shaped piston was used to achieve better fuel-air mixing and improved combustion performance. A high-pressure injector with a five-hole arrangement capable of producing a flat cone jet was developed by the researchers at TCU and used in this study. The needle valve of this common rail injector was driven by oil pressure, enabling hydrogen to be 
injected at a pressure of $20 \mathrm{MPa}$. The injection timing and duration were adjusted by controlling the timing and quantity of spill oil in the common rail injector drive line. The details of this newly developed high-pressure injector can be found in the reference [43]. The spark plug was located $20 \mathrm{~mm}$ away from the injector, and the hydrogen jet was aimed towards the spark plug gap, forming a jet-guided combustion system.

\subsection{SIBS sensor: Optical fibre-embedded spark plug}

In the previous spark plug sensor (Fig. 2), the ground electrode was modified with a sharp-edged electrode for stable ionic initiation and made separable from the thread reach, which could be attached again using screws. This design was adopted initially to make cleaning of the sapphire window and other maintenance easier, because the spark plug sensor was developed for use in the combustion of hydrocarbon fuels [39], in which deposits or fouling of the sapphire window occurred frequently. However, these modifications led to unstable spark formation outside of the measurement area, especially for high ambient pressures (Fig. 3). To overcome this issue, a new SIBS sensor was developed without modification to the thread reach or electrodes. In addition, the deposit on the sapphire window was minimal, because the plug was used only for the combustion of hydrogen fuel. In addition, this SIBS sensor is applicable to a production SI engine because it does not require any engine modifications.

Figure 4 shows the new fibre optic plug sensor developed from a commercially available spark plug (M-12 type) in which a 1.5-mm-diameter hole was drilled centrally along the spark plug body to accommodate the optical fibre and sapphire window assembly. The electrode tip where sapphire window was housed could be attached with the centre electrode through the threads cut on the both electrode tip and centre electrode. An optical ultraviolet (UV)-grade quartz fibre 
(core diameter: $1000 \mu \mathrm{m}$; outer diameter: $1250 \mu \mathrm{m}$ ) was housed along the centre electrode to collect light from the spark discharge. The sapphire window, which can be used safely under high-pressure conditions, was mounted at the tip of the centre electrode to provide passage for light from spark emission. The spark plug gap was maintained at $1.5 \mathrm{~mm}$ to generate a stable spark discharge. The optical fibre had a numerical aperture (NA) of 0.20 , and covered the area around the ground electrode. A small projection towards the centre electrode was made to facilitate spark discharge initiation; this also acted as the starting point of the ionic streamer during breakdown and arc phases. The discharge voltage and current were supplied to the fibre optic spark plug through a high-voltage power source and a coil-type ignition system in a practical SI engine. An Ocean Optics USB2000+ spectrometer was used to analyse the light emission from the spark plasma obtained through the optical fibre during spark discharge. The spectrometer equipped with a linear CCD array detector operating in the 350-850 nm spectral region with a spectral resolution of $0.37 \mathrm{~nm}$. The integration time used here is $150 \mu$ s from the onset of spark discharge; as this is found to be optimum duration to record strong atomic emission line of $\mathrm{H} \alpha, \mathrm{N}(\mathrm{I})$ and $\mathrm{O}(\mathrm{I})$ within the spark duration of around $2 \mathrm{~ms}$.

\section{Results and Discussion}

3.1 Effect of corresponding pressure during spark initiation on spectral calibration: Calibration $\underline{\text { map }}$

The local air excess ratio which can be defined as the ratio of the actual air-to-fuel ratio to the stoichiometric air-to-fuel ratio (simply the inverse of fuel/air equivalence ratio), near the spark plug at spark ignition timing can be measured through SIBS using a fibre optic spark plug. Prior to measuring the mixture distribution in the hydrogen engine, SIBS requires calibration to determine the correlation between the local air excess ratio and the intensities of the emission 
lines (i.e. $\mathrm{I}_{\mathrm{H}} / \mathrm{I}_{\mathrm{N}}$ ). To make a calibration curve, port fuel injection was used, which ensured a premixed charge of hydrogen and air. To investigate the effects of the corresponding ambient pressure during ignition (i.e. spark discharge) on the accuracy of fuel concentration measurements; the ignition timing was varied from $20^{\circ}$ to $0^{\circ}$ BTDC (before top dead centre) along with different throttle openings (50\% and $100 \%)$ over a range of preset or overall air excess ratios (i.e. overall relative air/fuel ratio) from 2.0 4.0. The experiments were repeated for 100 times for each operating condition and all the data presented throughout the study represent the average of 100 engine cycles.

Figure 5 shows the in-cylinder pressure history of the port fuel injected hydrogen combustion. The corresponding pressure during the onset of spark discharge at $(\mathrm{Ig} . \mathrm{T} .=) 20^{\circ}$ BTDC with $50 \%$ throttle was $1.03 \mathrm{MPa}$, whereas it was $2.2 \mathrm{MPa}$ for Ig.T. $=15^{\circ} \mathrm{BTDC}$ with a throttle opening of $100 \%$, which produced peak combustion pressure of $\sim 4.5 \mathrm{MPa}$. The durability and functionality of the optical fibre and sapphire window assembly was not affected adversely by this harsh environment, although the pressure variation had a significant effect on emission intensities, as shown in Fig. 6. Here, the integration time or the gate width of the spectrometer was $150 \mu$ sith no gate delay with respect to the onset of spark discharge. In Fig. 6, the atomic emission lines of $\mathrm{H}_{\alpha}$ at $656 \mathrm{~nm}, \mathrm{O}(\mathrm{I})$ at $777 \mathrm{~nm}, \mathrm{~N}(\mathrm{I})$ at $501 \mathrm{~nm}$ and at $745 \mathrm{~nm}$ were clearly recorded. The intensity of the $\mathrm{H}_{\alpha}$ line was due to electronically excited hydrogen dissociated from the fuel $\left(\mathrm{H}_{2}\right)$ molecules, while the emissions of $\mathrm{N}(\mathrm{I})$ and $\mathrm{O}(\mathrm{I})$ lines were obtained from electronically excited nitrogen and oxygen, respectively, dissociated from air. It can be seen in Fig. 6 that retarded spark timing (i.e. higher ambient pressure at ignition timing) resulted in decreased signal intensities (i.e. line emissions), as well as weaker background emissions (i.e. plasma or arc 
emission). This indicates that variations in ambient pressure inside the engine cylinder during different sparks lead to variation in spark discharge behaviour and plasma formation.

Figure 7 shows the effect of ambient pressure during spark initiation on background-corrected atomic emission intensities of $\mathrm{H}_{\alpha}, \mathrm{N}(\mathrm{I})$, and $\mathrm{O}(\mathrm{I})$. In spectroscopic measurements and analyses, it is important to subtract the background from the raw spectrum data, especially when the intensities of some elements become the subject of interest. Here, background was subtracted from the raw spectra following the method suggested by Proctor and Sherwood [44] to obtain the background-corrected intensities for $\mathrm{H}_{\alpha}, \mathrm{N}(\mathrm{I})$, and $\mathrm{O}(\mathrm{I})$ emission lines. Details of the calibration and background subtraction methods can be found in Ref. [41]. From Fig.6 it can be observed that the intensity of background emission was considerably higher underneath the atomic emission of $\mathrm{N}(\mathrm{I})$ at $501 \mathrm{~nm}$ compared to that of $\mathrm{N}(\mathrm{I})$ at $745 \mathrm{~nm}$ which will lead to greater inaccuracy when calculating background corrected peak intensity. Besides $\mathrm{N}(\mathrm{I})$ at $745 \mathrm{~nm}$ was considered to be free of interference from other nearby emissions unlike $\mathrm{N}(\mathrm{I})$ at $501 \mathrm{~nm}$. As a consequence, for intensity of the atomic emission of nitrogen $\mathrm{N}(\mathrm{I})$, the emission line at $745 \mathrm{~nm}$ was chosen for further analysis throughout the study. In Fig. 7, a significant effect of the corresponding pressure at ignition timing could be observed on the atomic emissions of $\mathrm{H}_{\alpha}, \mathrm{N}(\mathrm{I})$, and $\mathrm{O}(\mathrm{I})$. Especially, the spectral line intensity of $\mathrm{H}_{\alpha}(656 \mathrm{~nm})$ decreased more rapidly with pressure compared with NI $(745 \mathrm{~nm})$ and OI $(777 \mathrm{~nm})$, indicating a higher degree of pressure dependency for $\mathrm{H}_{\alpha}$. It is known that with higher pressure and density of atoms or molecules, interactions between the atoms or molecules increase, which produces a higher collision probability and intensified collisions. The decay time of atoms becomes shorter when excited atoms collide with and are knocked down from excited levels by other atoms before radiating 
spontaneously. A decrease in the decay time of the atoms or the molecules and higher collision probability reduce the line intensities and broaden the line widths.

Figure 8 shows the correlation of the air excess ratio with background-corrected atomic emission intensity ratio (also known as a calibration curve) as a function of pressure at different ignition timings under two throttle opening conditions for a preset air excess ratio of $\lambda=3.0$. A linear relationship was demonstrated between the air excess ratio and the intensity ratio for both $\mathrm{I}_{\mathrm{H}} / \mathrm{I}_{\mathrm{N}}$ and $\mathrm{I}_{\mathrm{H}} / \mathrm{I}_{\mathrm{O}}$ over all pressure values. In Fig. 8(a) the black thick line, a linear regression line for all the data sets, represents the correlation of air excess ratio with intensity ratio of $\mathrm{H} / \mathrm{N}$, regardless of the pressure dependency of the atomic emission. The standard deviation of the mean value of intensity ratios were calculated and all the values (standard deviation) found to lie within $\sigma=$ 0.5967. Higher intensity ratios for both $\mathrm{I}_{\mathrm{H}} / \mathrm{I}_{\mathrm{N}}$ and $\mathrm{I}_{\mathrm{H}} / \mathrm{I}_{\mathrm{O}}$ could be observed with a lower air excess ratio, $\lambda$, as the electronically excited hydrogen dissociated from the fuel $\left(\mathrm{H}_{2}\right)$ molecules increased with higher fuel concentration. Figure 8 shows that the calibration lines became steeper (i.e. absolute slopes became greater) when the pressure at spark discharge increased and also effect of pressure on atomic emission was less pronounced as the mixture became leaner (i.e. when air excess ratio $\lambda$ was increasing). A comparison between Fig. 8(a) and Fig. 8(b) reveals that the pressure dependence characteristics of $\mathrm{I}_{\mathrm{H}} / \mathrm{I}_{\mathrm{N}}$ differ from those of $\mathrm{I}_{\mathrm{H}} / \mathrm{I}_{\mathrm{O}}$.

From Fig. 8, the absolute slope or gradient of each calibration line was calculated and plotted against the pressure at ignition timing, as shown in Fig. 9. An increasing trend in absolute slope with pressure, $\mathrm{P}_{\mathrm{ig}}$ at ignition timing was observed though this pressure effect or the pressure dependency of spectral line intensity was found to be less significant at comparatively higher pressure $\left(\mathrm{P}_{\mathrm{ig}}\right.$ beyond $\left.2 \mathrm{MPa}\right)$. greater values than that for $\mathrm{I}_{\underline{\underline{H}}} / \underline{I}_{\underline{N}}$ which imply that, for a fixed value of pressure, $\mathrm{P}_{\underline{i}}$ or ignition 


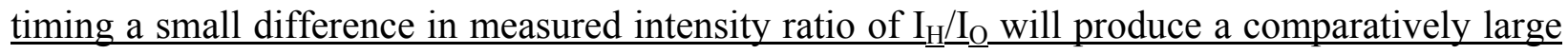
deviation between local air excess ratio $\left(\lambda_{\text {local }}\right)$ and preset or overall air excess ratio $\left(\lambda_{\text {preset }}\right)$. Therefore the correlation between the air excess ratio $\lambda$ with intensity ratio of $\mathrm{I}_{\underline{H}} / \underline{I}_{N}$ i.e. the black thick line in Fig. 8(a) was considered as the calibration line for measuring the local fuel concentration.

In the previous sections, a significant effect of pressure at ignition timing was observed on sparkinduced breakdown spectroscopic measurements and emission line characteristics under port injection conditions. Retarded spark timing (i.e. higher ambient pressure at the ignition site) resulted in lower spectral line intensities as well as weaker background emissions. These results are consistent with those from the literature (e.g. Phuoc [32] and Zhang et al. [45]). As reported in the literatures, at relatively higher pressures the expanding plasma is cooled quickly by the surrounding gas through enhanced collisional processes, leading to both a weak broadband continuum and spectral line intensities.

A calibration map which represents the correlation of air excess ratio with both intensity ratio and pressure at ignition timing was developed as shown in Fig.10, by taking into account the pressure dependency of spectral line intensity. This calibration map and calibration line (i.e. the black thick line in Fig. 8(a), that did not consider the effect of pressure at ignition timing on atomic emissions) were used for SIBS measurements.

Figure 11 shows a comparison of mean local air excess ratio measured with the use of the calibration map (Fig.10) with that measured using the calibration line (black thick line in Fig. 8 (a)) under port injection conditions. Here, for a fixed/preset air excess ratio, local air excess ratios were measured for different spark or ignition timing, varying from 20 to $0^{\circ} \mathrm{BTDC}$ along 
with different throttle openings (50\% and 100\%) over a range of air excess ratios from $2.0 \sim 4.0$ and mean local air excess ratios were plotted against the preset value $\left(\lambda_{\text {preset }}\right)$ in the figure. Although for a fixed ignition timing, the SIBS measurements made with calibration line produced completely different $\lambda_{\text {local }}$ from fixed/preset air excess ratio but averaging the values over ignition pressures $\mathrm{P}_{\mathrm{ig}}\left(\right.$ i.e. mean $\lambda_{\text {local }}$ for Ig.T. $=20 \sim 0^{\circ}$ BTDC) diminished this difference remarkably. Despite it can be clearly observed from Fig.11 that the deviation in $\lambda_{\text {local }}$ from $\underline{\text { fixed/preset air excess ratio }\left(\lambda_{\text {preset }}\right) \text { was comparatively large for measurement made without }}$ using calibration map whereas $\lambda_{\text {local }}$ obtained with calibration map leads to higher degree of closeness of local air excess ratios to the preset air excess ratios (true values). Furthermore, the coefficient of variation in local air excess ratio $\left(\mathrm{COV}_{\lambda \text { local }}\right)$ was significantly smaller for

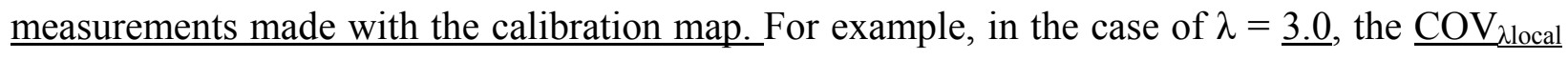
for measurements made with the calibration map was $\sim \underline{1 \%}$ whereas this increased to $\sim \underline{10 \%}$ for data obtained using the calibration line. This indicates that the quantitative measurement of fuel concentration through SIBS technique is strongly dependent on the strategy to generate calibration curve and the measurement accuracy can be improved significantly when the pressure dependency of atomic emissions is taken into account.

\subsection{Local air excess ratio measurement in a direct-injection hydrogen engine}

Quantitative measurements of fuel concentration around the spark gap location at the time of ignition in a jet-guided direct-injection hydrogen research engine (Fig.1) were conducted for both PI and DI strategies using the same spark plug sensor (Fig. 4). The experiments were performed with different air excess ratio varying from 2.0 4.0; and to achieve an axially stratified charge, the start of injection (SOI) was varied from $120^{\circ} \mathrm{BTDC}$ to $35^{\circ} \mathrm{BTDC}$ while MBT (minimum advance for best torque) timing was considered as an ignition strategy. The in- 
cylinder pressure history and rate of heat release (ROHR) for hydrogen combustion with an air excess ratio, $\lambda=4.0$ are shown in Fig. 12. Here, it is evident that cylinder pressure and heat release rate rise rapidly with the retardation of injection timing. This may be attributed to the fact that with direct injection condition the mixture became locally fuel-rich and the degree of richness increased with delayed start of injection leading to rapid burning of the mixture. To confirm this local stratification of the fuel mixture during ignition, SIBS measurements were carried out and the local air excess ratios was plotted against varying injection timing (Fig. 13). With retarded injection timing, i.e. when the SOI was delayed from $120^{\circ} \mathrm{BTDC}$ to $35^{\circ} \mathrm{BTDC}$, the mixture in the vicinity of the spark gap location became successively richer during spark timing at MBT. This phenomenon is evident in both Fig. 13(a) and Fig. 13(b) because the local air excess ratio $\left(\lambda_{\text {local }}\right)$ decreased gradually with retarded SOI. However, direct injection (DI) conditions generated a higher local air excess ratio $\left(\lambda_{\text {local }}\right)$ compared with port injection (PI) conditions when the pressure dependency of the spectral emissions was ignored (Fig. 13(a)). This measurement inaccuracy can be eliminated by taking into account the effect of ambient pressure on atomic emission intensity, as shown in Fig. 13(b).

Figure 14(a) shows the results for local air excess ratios obtained without considering the pressure dependency of atomic emissions, whereas Fig. 14(b) shows the results obtained using the calibration map. It can be seen from Fig. 14(a) that the mixture at the spark gap seems to be comparatively leaner for the direct injection strategy with $\mathrm{SOI}=120^{\circ}$ to $50^{\circ} \mathrm{BTDC}$ compared with that for PI conditions. Nevertheless, the local air excess ratio $\left(\lambda_{\text {local }}\right)$ around the spark gap region for the jet-guided stratified operation of the engine should be much lower (as the mixture was stratified and became locally rich) than the local air excess ratio $\left(\lambda_{\text {local }}\right)$ for port injection conditions. This discrepancy could be attributed to ignoring the pressure dependency of atomic 
emissions because for measurements made through the average calibration line (the black thick line in Fig.8(a)), the value of local air excess ratio $\left(\lambda_{\text {local }}\right)$ would be greater than the actual when actual air excess ratio lies within the value of 3.0. In Fig. 14(b), most of the data for local air excess ratio $\left(\lambda_{\text {local }}\right)$ for direct injection condition lie within the value of 3.0 and found to be lower than that for PI, indicating the formation of a richer mixture around the spark gap region with the jet-guided stratified operation. This result is consistent and indicates improvement in measurement accuracy due to taking into account the effects of in-cylinder ambient pressure at ignition timing on the spectral line emissions.

\section{Conclusions}

Quantitative measurements of fuel concentration were conducted in a direct-injection hydrogen spark-ignition research engine through spark-induced breakdown spectroscopy (SIBS) technique. A new sensor with an optical fibre housed in the centre electrode of the spark plug was developed from a commercially available M12-type spark plug with no major modification to the electrodes, leading to stable spark formation. The main focus of this study was to characterise the effects of ambient pressure at ignition timing on atomic emissions and to improve the accuracy of the SIBS measurements by taking into account the pressure dependency of atomic emissions. Summarising the results, the following conclusions can be drawn:

1. The newly developed fibre optic spark plug sensor was used successfully in a DISI research engine. The plug sensor had better durability and required less maintenance when applied to hydrogen combustion.

2. A linear relationship (calibration line) was demonstrated between air excess ratio and intensity ratio for both $\mathrm{I}_{\mathrm{H}} / \mathrm{I}_{\mathrm{N}}$ and $\mathrm{I}_{\mathrm{H}} / \mathrm{I}_{\mathrm{O}}$ over all pressure values. A significant effect of the 
corresponding pressure at ignition timing was observed on SIBS measurements and emission line characteristics. Retardation in spark timing (i.e. higher ambient pressure at the ignition site), resulted in lower spectral line intensities as well as weaker background emissions. This indicates the variation in spark discharge behaviour and plasma formation with variation in ambient pressure inside the engine cylinder during spark timing variation. At relatively higher pressures, the cooling of the expanding plasma was quicker due to collisional processes with the surrounding gas, leading to both a weaker broadband continuum and atomic emissions.

3. A calibration MAP, representing the correlation of air excess ratio with both intensity ratio and pressure at ignition timing, was developed by taking into account the effect of the corresponding pressure at ignition timing on spectral line intensity for quantitative measurements of local air excess ratio in a research engine. Local stratification of the fuel mixture in the vicinity of the spark gap location associated with direct injection strategies was confirmed using the newly developed spark plug sensor. The COV of local air excess ratio was considerably smaller for measurements made through the calibration map. This indicates that the accuracy of measurements of local air excess ratio through the spark plug sensor can be improved significantly when the pressure dependency of atomic emissions is taken into account.

\section{Acknowledgments}

This work was supported by the Council for Science, Technology and Innovation (CSTI), Crossministerial Strategic Innovation Promotion Program (SIP), "energy carrier" Funding agency: Japan Science and Technology Agency (JST).

\section{Reference}


[1] Karim G. Hydrogen as a spark ignition engine fuel. Int J Hydrogen Energy 2003;28(5):569-77.

[2] Verhelst S. Recent progress in the use of hydrogen as a fuel for internal combustion engines. Int $J$ Hydrogen Energy 2014;39(2):1071-85.

[3] Frolov SM, Medvedev SN, Basevich VY, Frolov FS. Self ignition of hydrocarbon-hydrogen-air mixtures. Int J Hydrogen Energy 2013;38(10):4177-84.

[4] Wang Z, Naterer GF. Integrated fossil fuel and solar thermal systems for hydrogen production and CO2 mitigation. Int J Hydrogen Energy 2014;39(26):14227-33.

[5] Salvi BL, Subramanian KA. Experimental investigation on effects of compression ratio and exhaust gas recirculation on backfire, performance and emission characteristics in a hydrogen fuelled spark ignition engine. Int J Hydrogen Energy 2016;41(13):5842-55.

[6] Briguglio N, Ferraro M, Brunaccini G, Antonucci V. Evaluation of a low temperature fuel cell system for residential CHP. Int J Hydrogen Energy 2011;36:8023e9.

[7] Hwang JJ, Zou ML. Development of a proton exchange membrane fuel cell cogeneration system. J Power Sources 2010;195:2579e85.

[8] Onovwiona HI, Ugursal VI. Residential cogeneration systems: review of the current technology. Renew Sust Energ Rev 2006;10:389-431.

[9] Lipman TE, Edwards JL, Kammen DM. Fuel cell system economics: comparing the costs of generating power with stationary and motor vehicle PEM fuel cell systems. Energ Policy 2004;32:101-25.

[10] Obara S, Tanno I. Study on capacity optimization of PEM fuel cell and hydrogen mixing gas-engine compound generator. Int J Hydrogen Energy 2007;32(17):4329-4339.

[11] White CM, Steeper RR, Luts AE. The hydrogen-fueled internal combustion engine: a technical review. Int J of Hydrogen Energy 2006;31(10):1292-305.

[12] Mohammadi A, Shioji M, Nakai Y, Ishikura W, Tabo E. Performance and combustion characteristics of a direct injection SI hydrogen engine. Int J Hydrogen Energy 2007; 32(2):296-304.

[13] Rottengruber H, Berckmu“ ller M, Elsa“ sser G, Brehm N, Schwarz C. Direct-injection hydrogen SIengine - operation strategy and power density potential. SAE paper no. 2004-01- 2927; 2004.

[14] White CM. A qualitative evaluation of mixture formation in a direct-injection hydrogen-fuelled engine. SAE Paper No. 2007-01-1467. 2007.

[15] Duan J, Liu F, Sun B. Backfire control and power enhancement of a hydrogen internal combustion engine. Int J Hydrogen Energy 2014;39(9):4581-9.

[16] Oikawa M, Ogasawara Y, Kondo Y, Sekine K, Takagi Y, Sato Y. Optimization of hydrogen jet configuration by single hole nozzle and high speed laser shadowgraphy in high pressure direct injection hydrogen engines. Int J Automotive Engineering 2012;3:1-8. 
[17] Hall MJ, Koenig M. A fiber-optic probe to measure precombustion in-cylinder fuel-air ratio fluctuations in production engines. Proc Combust Inst 1996;26(2):2613-8.

[18] Koenig M. and Hall MJ. Measurements of Local In-Cylinder Fuel Concentration Fluctuations in a Firing SI Engine. SAE Paper No.971644. 1997.

[19] Koenig M. and Hall MJ. Cycle-Resolved Measurements of Pre-Combustion Fuel Concentration Near the Spark Plug in a Gasoline SI Engine. SAE Paper No.981053. 1998.

[20] K. Kawamura, T. Suzuoki, A. Saito, T. Tomoda, M. Kanda, Development of instrument for measurement of air-fuel ratio in vicinity of spark-plug (application to DI gasoline engine), JSAE Rev. 19 (1998) 305-310.

[21] S. Yoshiyama, Y. Hamamoto, E. Tomita, K. Minami, Measurement of hydrocarbon fuel concentration by means of infrared absorption technique with $3.39 \mu \mathrm{m}$ He-Ne Laser, JSAE Rev. 17 (1996) 339-345.

[22] E. Tomita, N. Kawahara, M. Shigenaga, A. Nishiyama, R.W. Dibble, In Situ measurement of hydrocarbon fuel concentration near a spark plug in an engine cylinder by $3.392 \mu \mathrm{m}$ infrared laser absorption method: discussion of applicability with a homogeneous methane-air mixture, Meas. Sci. Technol. 14 (2003) 1350-1356.

[23] E. Tomita, N. Kawahara, A. Nishiyama, M. Shigenaga, In Situ measurement of hydrocarbon fuel concentration near a spark plug in an engine cylinder by $3.392 \mu \mathrm{m}$ infrared laser absorption method: application to actual engine, Meas. Sci. Technol. 14 (2003) 1357-1363.

[24] E. Tomita, N. Kawahara, S. Yoshiyama, A. Kakuho, T. Itoh, Y. Hamamoto, In-Situ fuel concentration measurement near spark-plug in spark-ignition engines by $3.39 \mu \mathrm{m}$ infrared laser absorption method, Proc Combust Inst 2002;29(1):735-741.

[25] A. Nishiyama, N. Kawahara, E. Tomita, In-Situ Fuel Concentration Measurement near Spark Plug by $3.39 \mu \mathrm{m}$ Infrared Absorption Method (Application to Spark Ignition Engine). SAE Paper No.2003-011109. 2003.

[26] Kawahara N, Tomita E, Kadowaki T, Honda T, Katashiba H. In situ fuel concentration measurement near a spark plug in a spray-guided direct-injection spark-ignition engine using infrared absorption method, Exp Fluids 2010;49(4):925-36.

[27] N. Kawahara, E. Tomita, K. Hayashi, M. Tabata, K. Iwai, R. Kagawa, Cycle-resolved measurements of the fuel concentration near a spark plug in a rotary engine using an in situ laser absorption method, Proc Combust Inst 2007;31(2):3033-3040.

[28] Tomita E, Hamamoto Y, Yoshiyama S, Toda H. Measurement of fuel concentration distribution of transient hydrogen jet and its flame using planar laser induced fluorescence method. JSAE Rev 1998;19(4):329-35. 
[29] Blotevogel T, Hartmann M, Rottengruber H, Leipertz A. Tracer-based laser-induced fluorescence measurement technique for quantitative fuel/air-ratio measurements in a hydrogen internal combustion engine. Appl Opt 2008;47(35):6488-96.

[30] Kaiser S, White CM. PIV and PLIF to evaluate mixture formation in a direct-injection hydrogenfuelled engine. SAE Paper No.2008-01-1034. 2008.

[31] F. Ferioli, P.V. Puzinauskas, S.G. Buckley, Laser-induced breakdown spectroscopy for on-line engine equivalence ratio measurements. Appl Spectro 2003;57(9):1183-1189.

[32] Phuoc TX. Laser-induced spark for simultaneous ignition and fuel-to-air ratio measurements. Opt Lasers Eng 2006;44(6):520-34.

[33] Shudo T, Oba S. Mixture distribution measurement using laser induced breakdown spectroscopy in hydrogen direct injection stratified charge. Int J Hydrogen Energy 2009;34(5):2488-93.

[34] N. Kawahara, J.L. Beduneau, T. Nakayama, E. Tomita, Y. Ikeda, Spatially, temporally and spectrally resolved measurement of laser induced plasma in air. Appl. Phys., B Laser Opt. 2007;86(4):605-614.

[35] Y. Ikeda, A. Nishiyama, N. Kawahara, T. Nakayama, E. Tomita, Local Equivalence Ratio Measurement of CH4/air and C3H8/air Laminar Flames With and Without Flame Front by LIBS. Sect. 5, LIBS2006, 2006.

[36] R.M. Merer, J.S. Wallace, Spark Spectroscopy for Spark Ignition Engine Diagnostics. SAE Paper No. 950164. 1995.

[37] K. Kuwahara, H. Ando, Diagnostics of in-cylinder flow, mixing and combustion in gasoline engines. Meas. Sci. Technol. 2000;11:95-111.

[38] T.D. Fansler, B. Stojkovic, M.C. Drake, M.E. Rosalik, Local fuel concentration measurements in internal combustion engines using spark-emission spectroscopy. Appl. Phys., B Laser Opt. 2002;75(4):577-590.

[39] N. Kawahara, E. Tomita, S. Takemoto, Y. Ikeda. Fuel concentration measurement of premixed mixture using spark-induced breakdown spectroscopy. Spectro Acta Part B 2009;64(10):1085-1092

[40] Roy MK, Nobuyuki K, Tomita E, Fujitani T. Jet-guided combustion characteristics and local fuel concentration measurements in a hydrogen direct-injection spark-ignition engine. Proc Combust Inst 2013;34:2977-84.

[41] Abdul Rahman MT, Kawahara N, Tsuboi K, Tomita E. Visualization and concentration measurement of a direct injection hydrogen jet in a constant-volume vessel using spark-induced breakdown spectroscopy. Int J Hydrogen Energy 2014;39(31):17896-17905.

[42] Abdul Rahman MT, Kawahara N, Tsuboi K, Tomita E. Effect of ambient pressure on local concentration measurement of transient hydrogen jet in a constant-volume vessel using spark-induced breakdown spectroscopy. Int J Hydrogen Energy 2015;40(13):4717-4725. 
[43] Yamane K, Nogami M, Umemura Y, and Oikawa M. Development of High Pressure H2 Gas Injectors, Capable of Injection at Large Injection Rate and High Response Using a Common-rail Type Actuating System for a 4-cylinder, 4.7-liter Total Displacement, Spark Ignition Hydrogen Engine. SAE Paper No.2011-01-2005. 2011.

[44] Proctor A, Sherwood PMA. Data analysis techniques in X-ray photoelectron spectroscopy. Anal Chem Jan. 1982;54(1):13-9.

[45] Zhang S, Yu X, Li F, Kang G, Chen L, Zhang X. Laser induced breakdown spectroscopy for local equivalence ratio measurement of kerosene/air mixture at elevated pressure. Opt Lasers Eng 2012;50(6):877-882.

[The English in this document has been checked by at least two professional editors, both native speakers of English. For a certificate, please see:

http://www.textcheck.com/certificate/NZiC0G] 


\section{List of Table}

Table 1

Engine Specifications

\begin{tabular}{ll}
\hline Engine displacement & $1054 \mathrm{cc}$ \\
Bore x stroke & $108 \mathrm{~mm}$ x 115 mm \\
Compression ratio & $13: 1$ \\
Combustion chamber type & Bowl \\
Engine speed & $1000 \mathrm{rpm}$ \\
Throttle opening & $50 \%, 100 \%$ \\
Swirl ratio & 2.2 \\
Cooling system & Water cooled \\
Ignition system & Spark ignition \\
Injection system & PFI, DI \\
\hline
\end{tabular}




\section{$\underline{\text { List of Figures }}$}
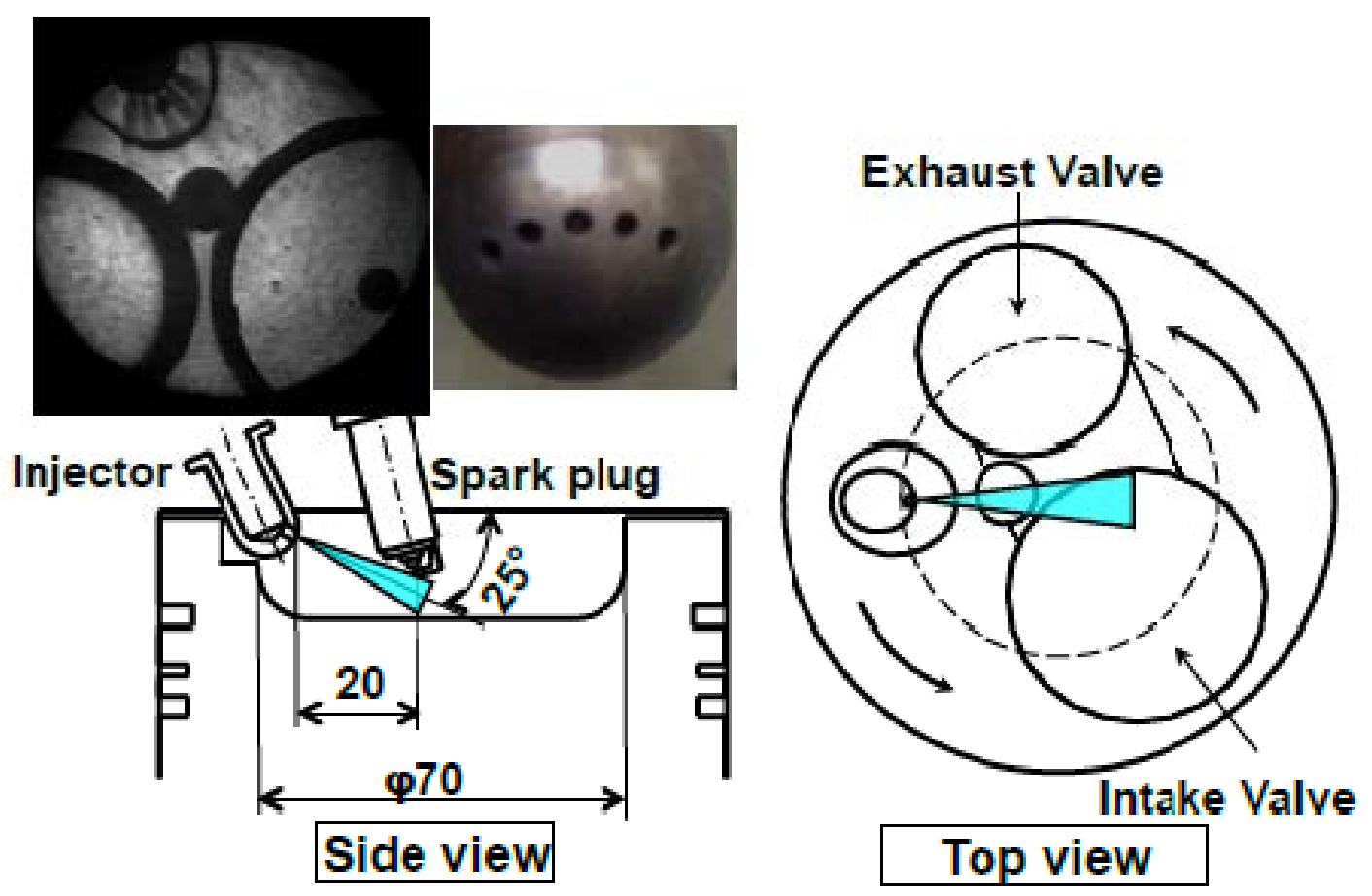

Fig. 1 Geometry of the combustion chamber and relative orientation of spark plug and injector 


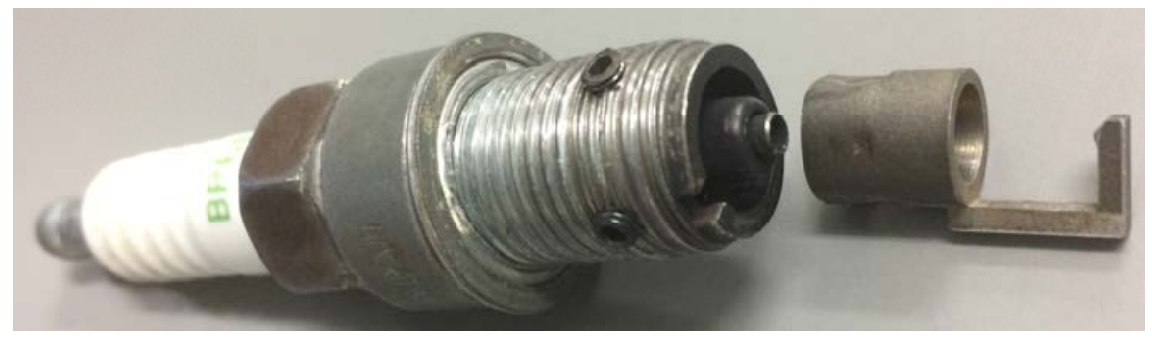

Fig. 2 Previous fibre optic spark plug sensor with separable ground electrode

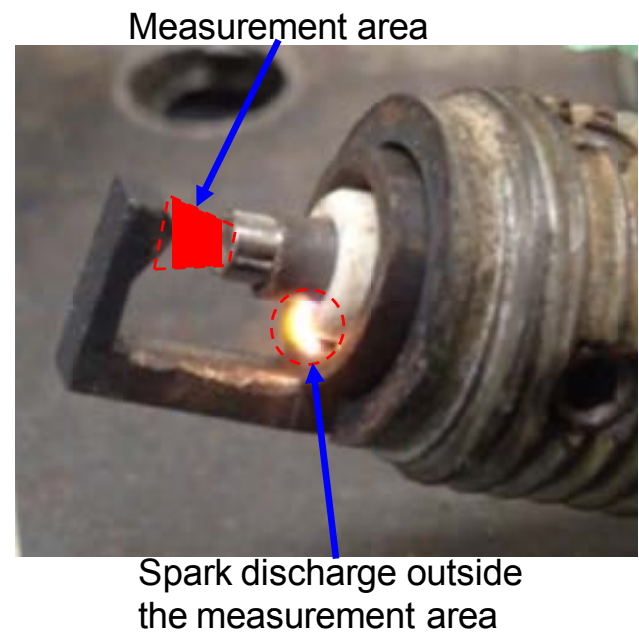

Fig. 3 Spark discharge outside of measurement area in case of previous spark plug sensor

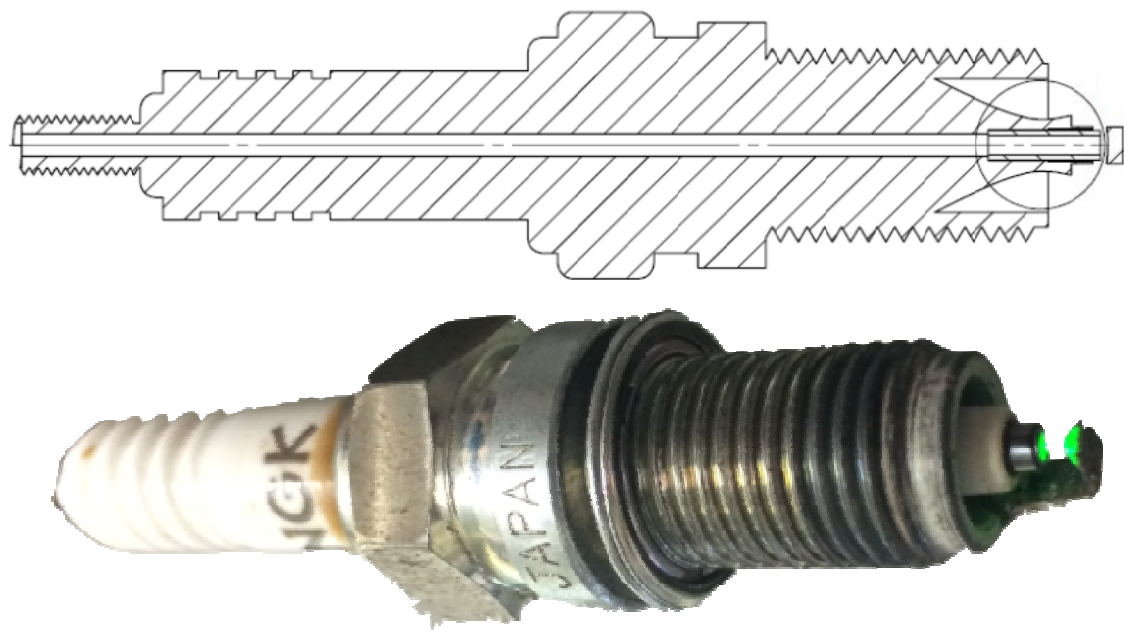

Fig. 4 New spark plug sensor (bottom fig.: laser light passing through the optical fibre housed in the center electrode) 


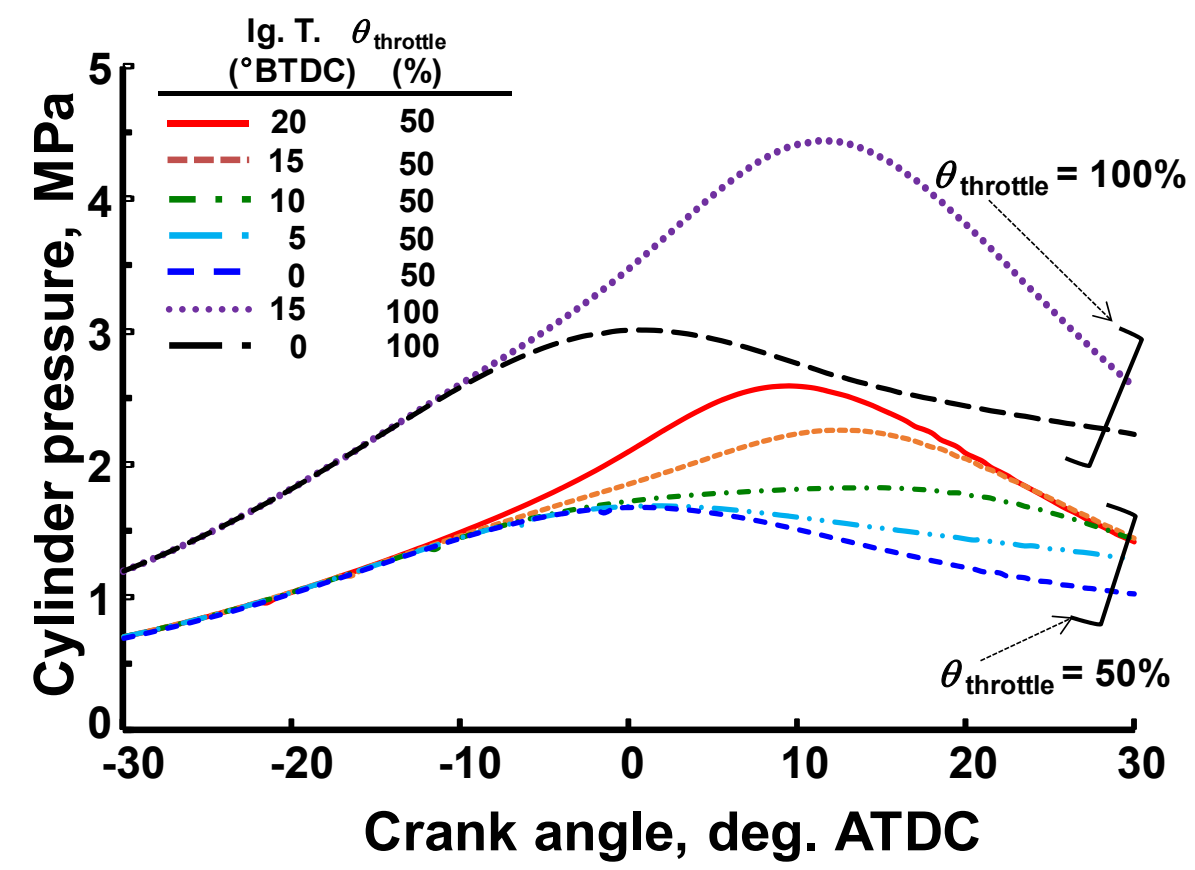

Fig.5. In-cylinder pressure history for hydrogen combustion with $\lambda=3$ and different throttle opening

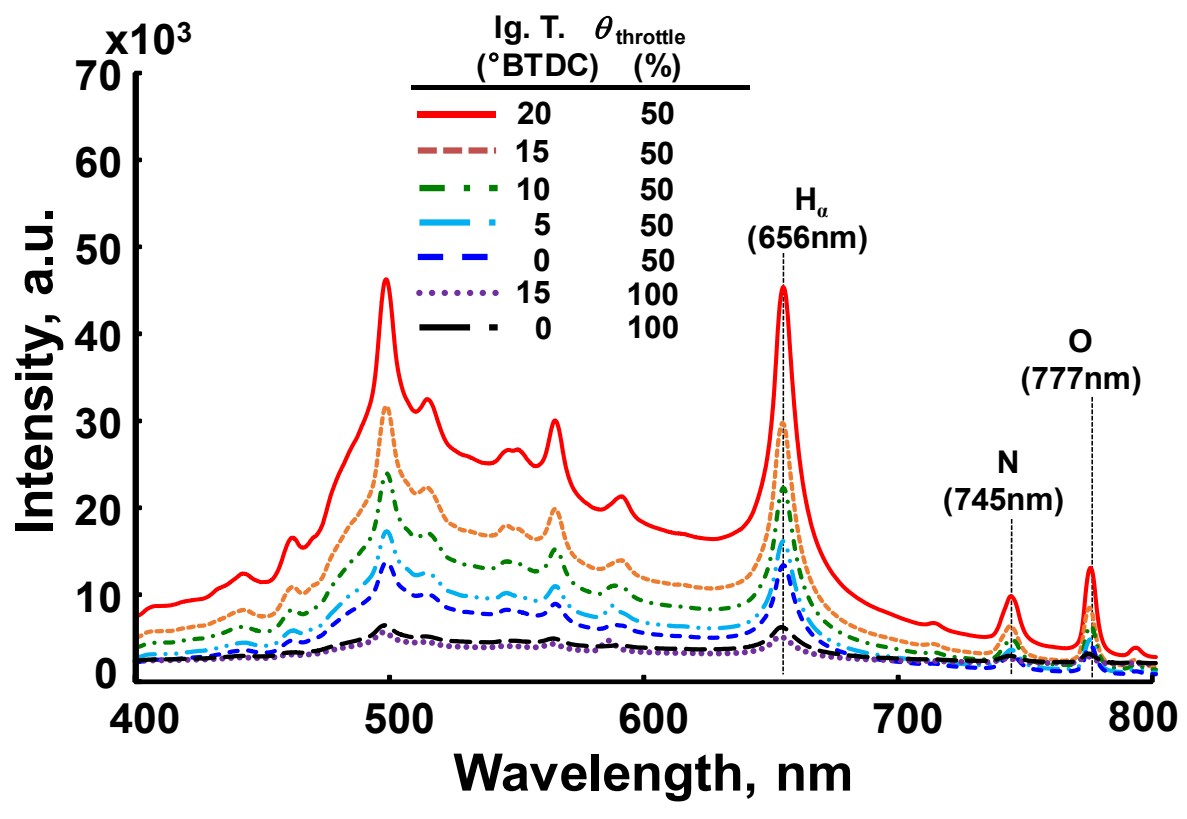

Fig.6. Spark emission spectra for hydrogen combustion with $\lambda=3$ and varying ignition timing 


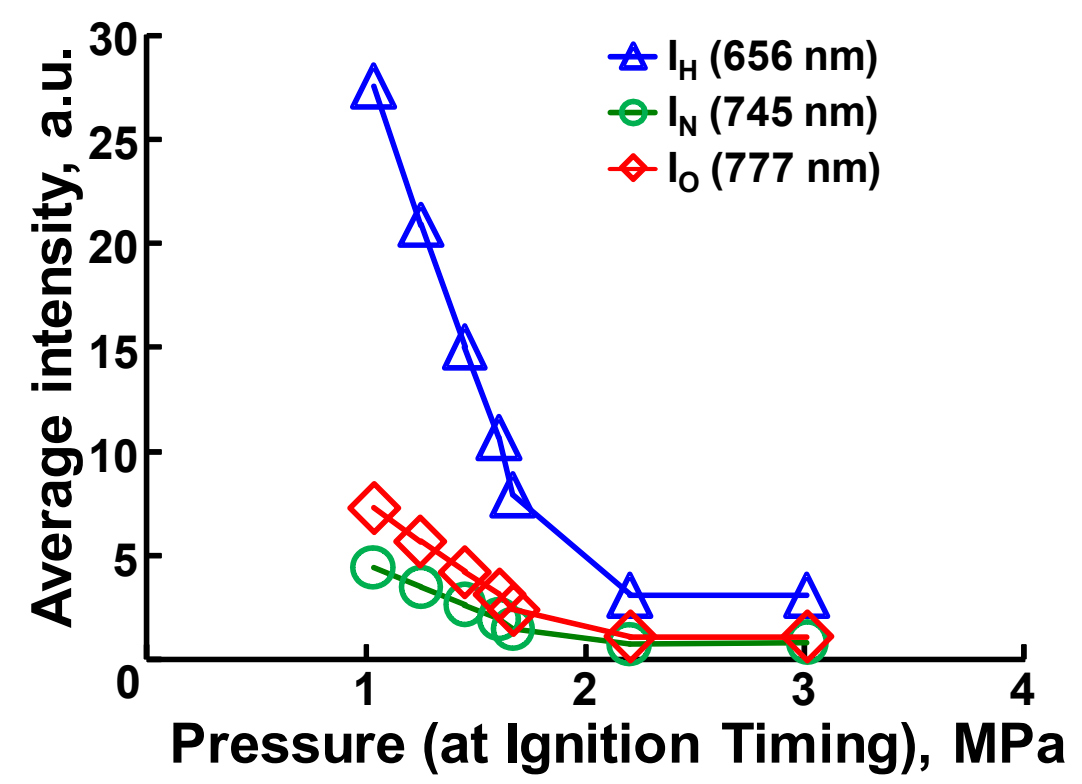

Fig.7. Variation in atomic emission intensities of $\mathrm{H}_{\alpha}, \mathrm{N}(\mathrm{I})$ and $\mathrm{O}(\mathrm{I})$ with ambient pressure during spark initiation

(a)

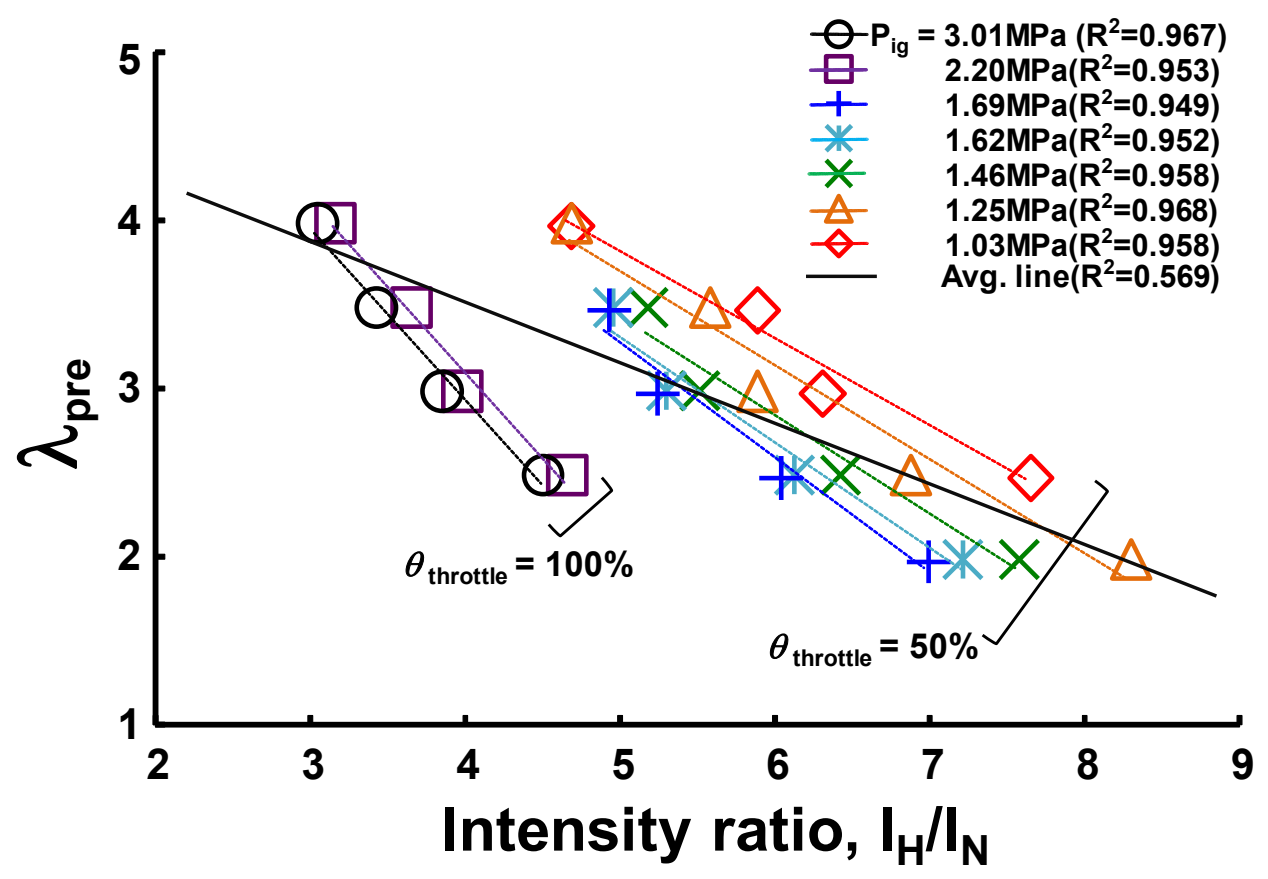


(b)

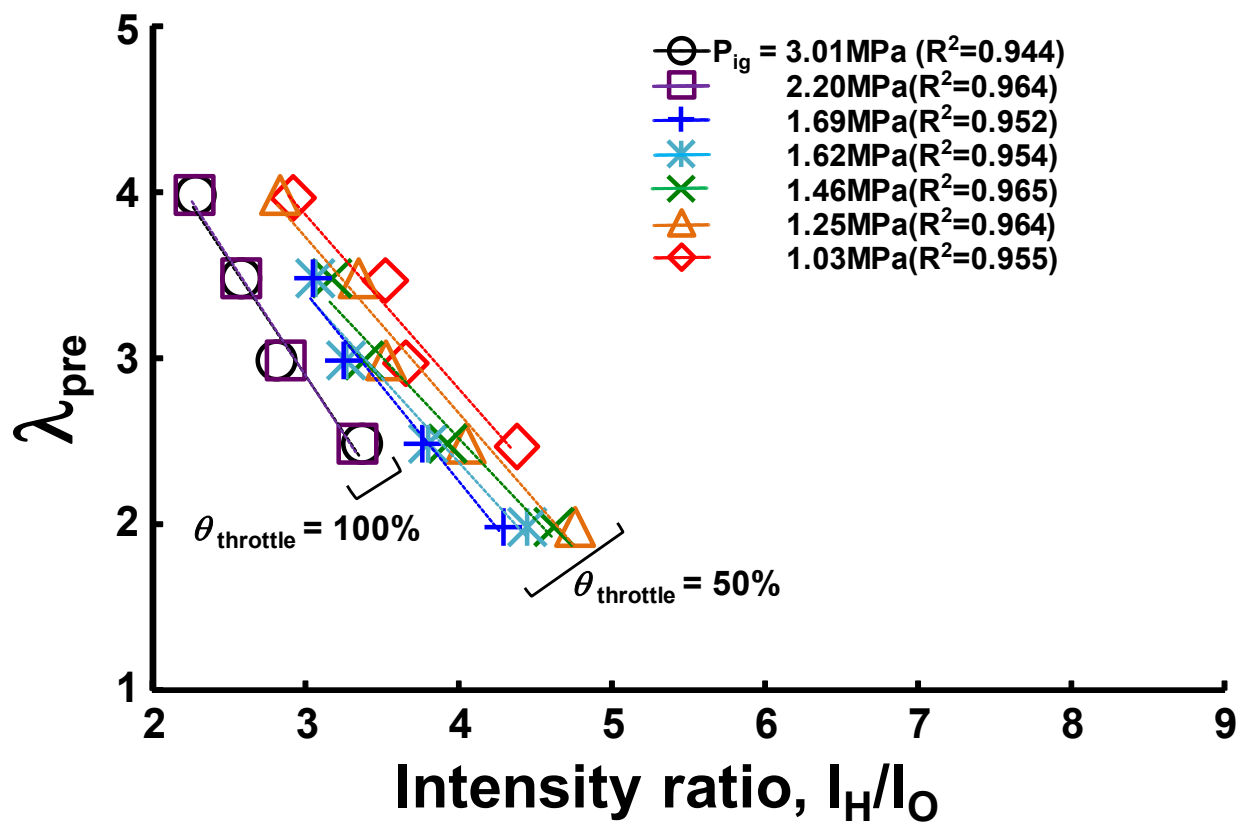

Fig. 8 Correlation of the air excess ratio $\lambda$ with atomic intensity ratio (a) of $\mathrm{H}_{\alpha}$ to $\mathrm{N}$, (b) with that of the $\mathrm{H}_{\alpha}$ to $\mathrm{O}$ at different ambient pressure during spark initiation

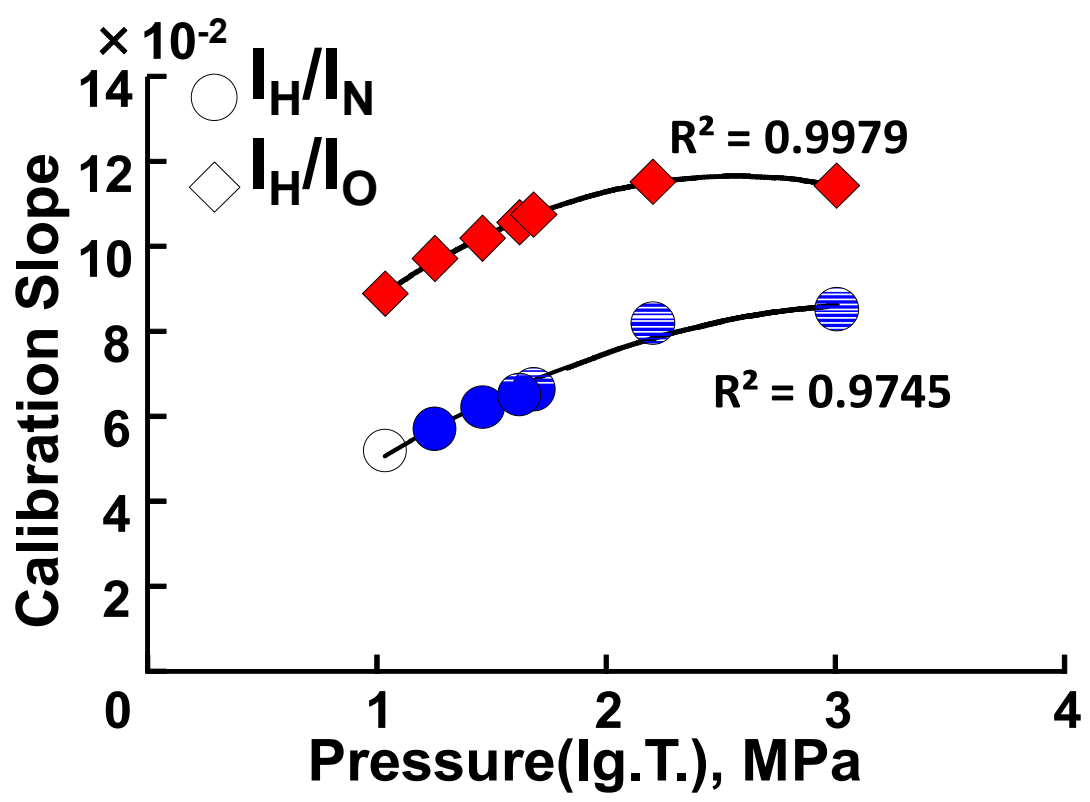

Fig.9 Effect of pressures at ignition timing on slope of the calibration lines 


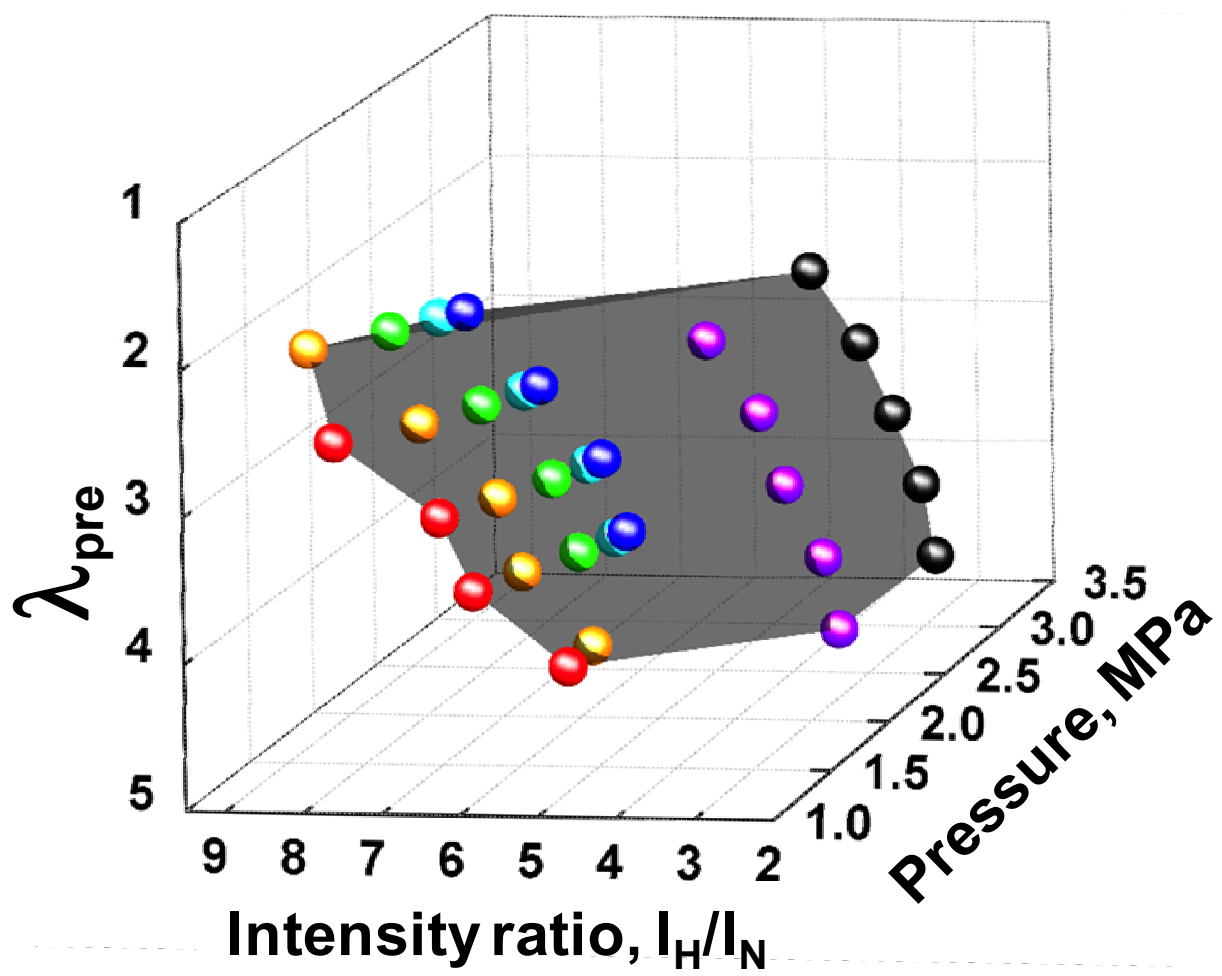

Fig.10 Calibration map or correlation of air excess ratio with intensity ratio and pressure at ignition timing

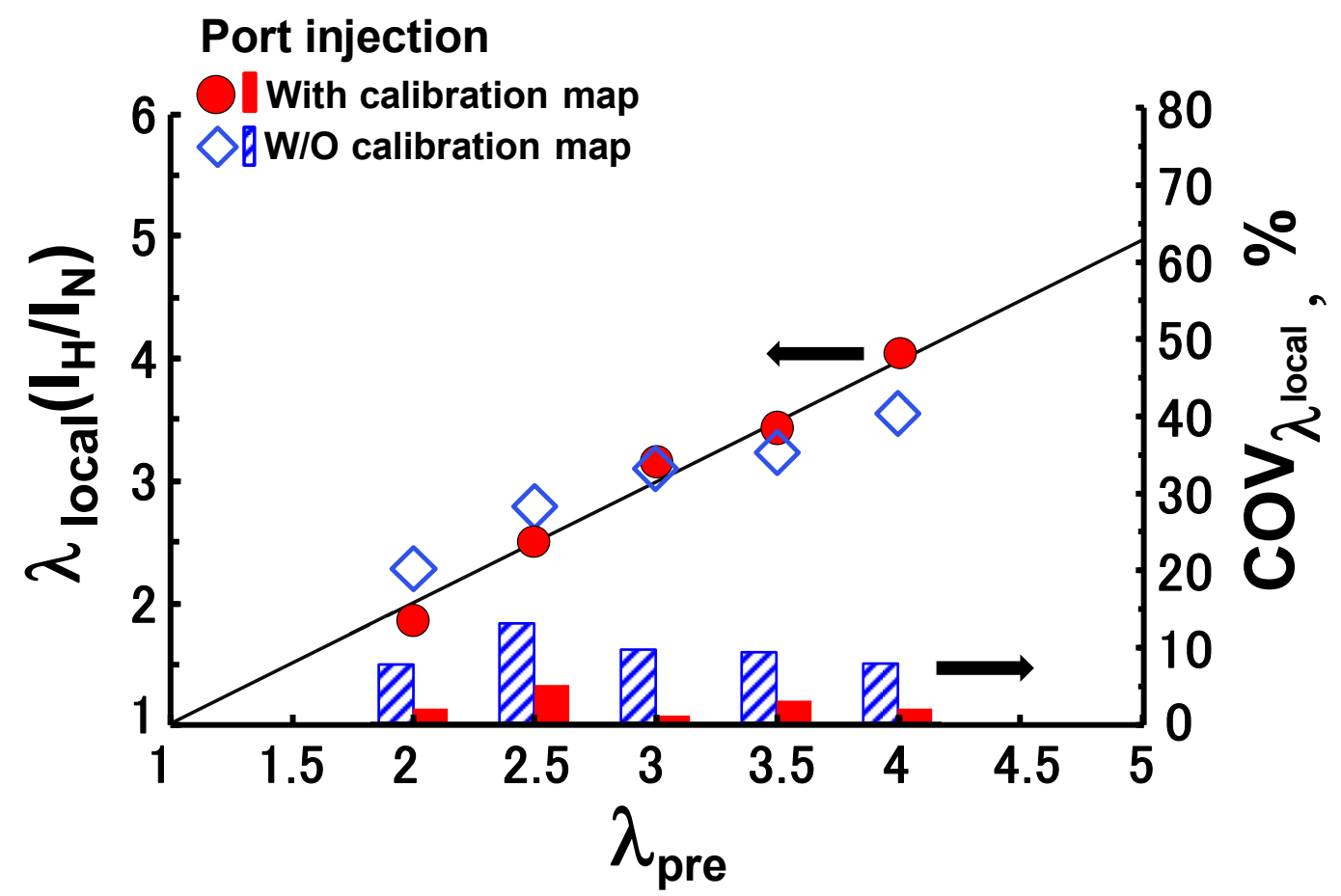

Fig.11 Improvement in the accuracy of SIBS measurement through the use of calibration map under port injection condition 


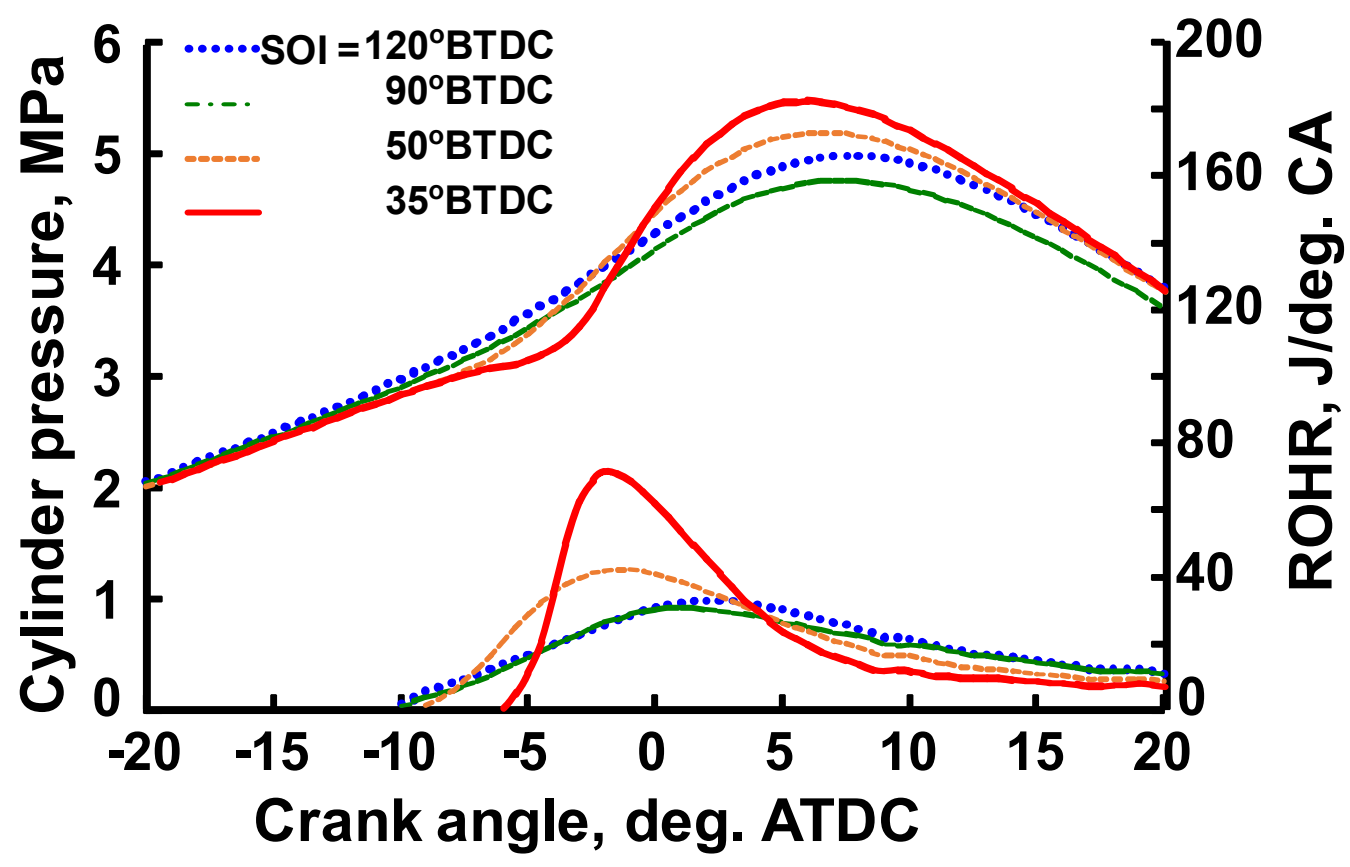

Fig.12 In-cylinder pressure history and rate of heat release (ROHR) with air excess ratio, $\lambda=4.0$ and varying injection timing 
(a)

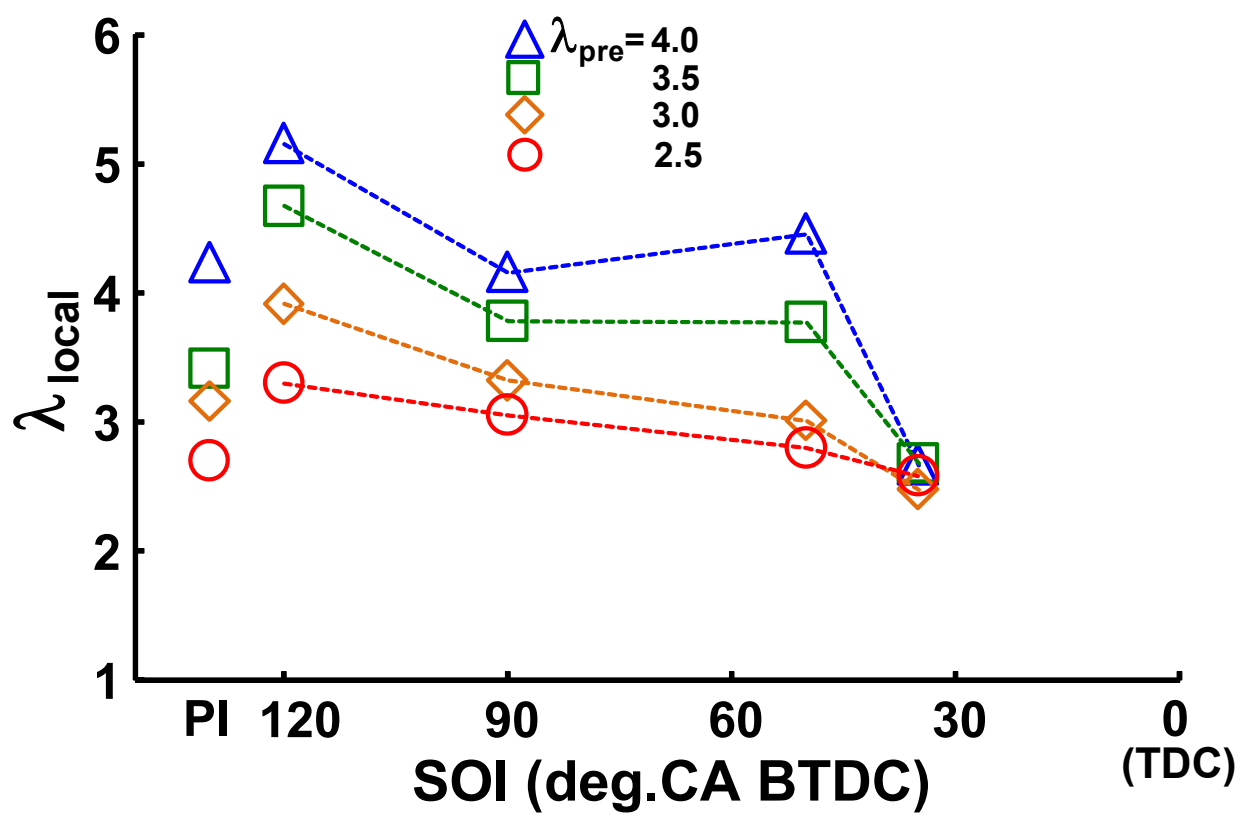

(b)

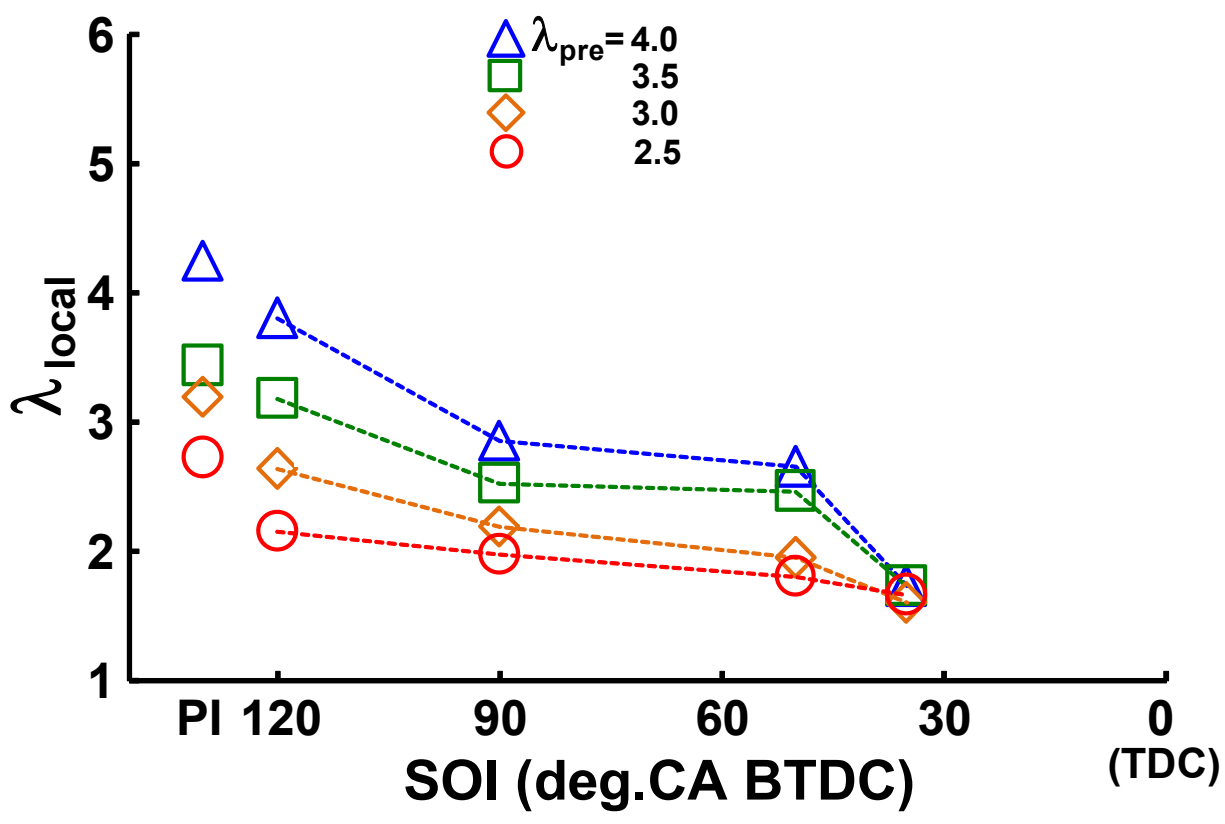

Fig.13 Variation of local air excess ratio $\left(\lambda_{\text {local }}\right)$ with injection timing (a) without considering pressure dependency, (b) measurements with calibration map 


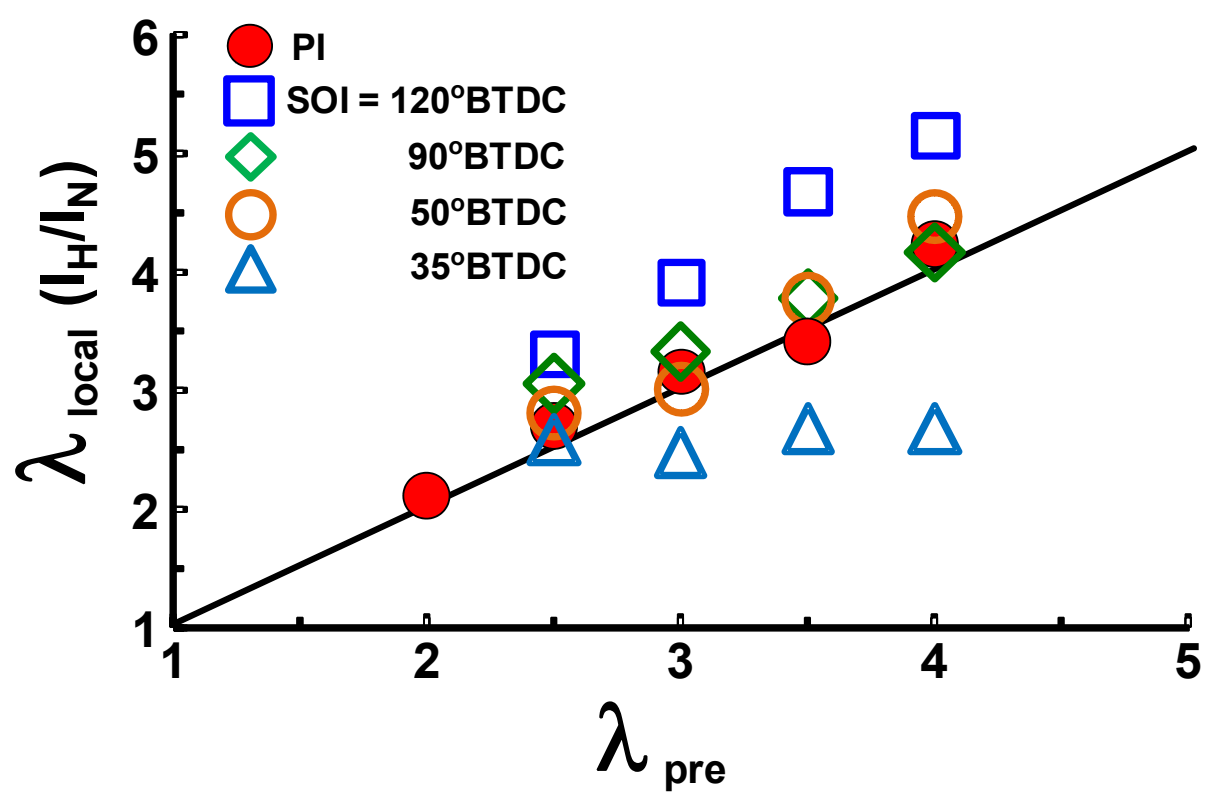

(a) Without considering pressure dependency of spectral emission

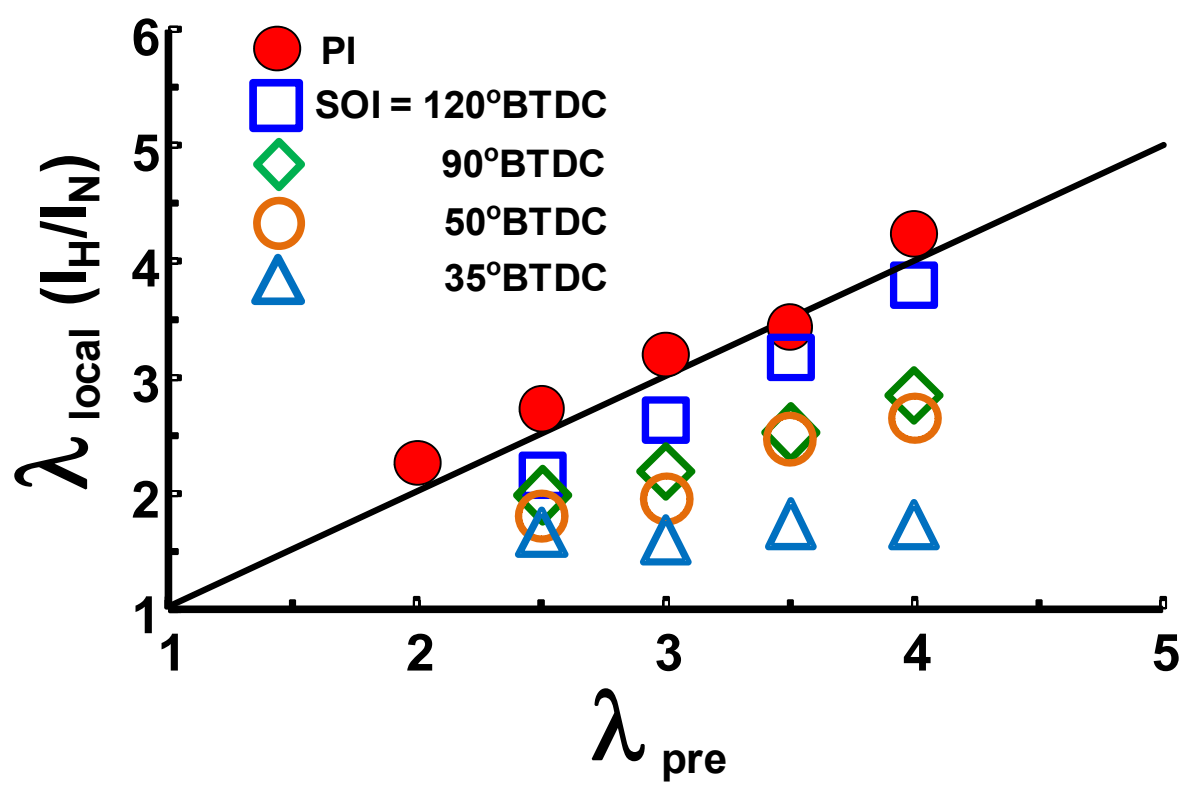

(b) With calibration map

Fig. 14 Effect of pressure dependency of spectral emission on SIBS measurements of local air excess ratio with different injection strategies 